\title{
Prevalence of diverticular disease of the colon in patients with ischaemic heart disease
}

\author{
K. J. FOSTER, G. HOLDSTOCK, P. J. WHORWELL, P. GUYER, AND \\ RALPH WRIGHT ${ }^{1}$
}

From Southampton University Hospitals, Southampton

SUMMARY In view of the similar patterns of incidence of diverticular disease of the colon (DD) and ischaemic heart disease (IHD) in different communities, the prevalence of diverticular disease was investigated in male patients after recovery from acute myocardial infarction. A significantly higher prevalence of DD was found among infarct patients $(57 \%)$ than among male control subjects $(25 \%)$ matched for age and social class.

Recently, considerable attention has been given to the role of dietary fibre in maintaining health (Lancet, 1977). Dietary fibre alters gastric emptying time and may alter the rate of absorption (Jenkins et al., 1977) of foodstuffs as well as decreasing bowel transit time and intracolonic pressure (Findlay et al., 1974). In western industrialised countries, less crude fibre is eaten than in many of the developing countries (Trowell, 1972).

Deficiency of dietary fibre has been implicated in the development of diverticular disease of the colon, which is much commoner in industrialised societies than in the developing countries. In addition, treatment of diverticular disease with supplements of fibre is reported to lead to an improvement in symptoms and normalisation of colonic motor activity (Findlay et al., 1974; Brodribb, 1977).

Both diverticular disease and ischaemic heart disease have become much more prevalent in western industrialised countries, but remain less common in the developing countries, suggesting that deficiency of dietary fibre might be a common aetiological factor (Trowell, 1972; Trowell et al., 1974). Were this so, one might expect an increased prevalence of diverticular disease among patients with ischaemic heart disease, but this has not been investigated. We have therefore investigated the prevalence of asymptomatic diverticular disease in patients with ischaemic heart disease and matched control subjects.

\footnotetext{
${ }^{1}$ Address for correspondence: Professor Ralph Wright, Professorial Medical Unit, Level F, Centre Block, Southampton General Hospital, Southampton SO9 4XY.
}

Received for publication 4 May 1978

\section{Methods}

\section{SUBJECTS}

Forty consecutive male patients attending hospital medical outpatient clinics three to four months after an acute myocardial infarction were prospectively studied. Two subjects seen during the study declined to participate. The diagnosis of acute myocardial infarction was previously made in each case in hospital on the basis of typical history, sequential electrocardiographic changes, and a raised plasma aspartate aminotransferase concentration. Healthy control subjects were recruited with the co-operation of a local organisation (the Ordnance Survey), who examined their medical records and provided a list of 964 males in their work force of appropriate age with no recorded cardiovascular disease or other chronic disease. Control subjects were selected randomly from this list and interviewed.

The first 40 subjects with no historical evidence of ischaemic heart disease and no abnormalities on a standard 12-lead electrocardiogram of corresponding age to the patients entered the trial. Ten subjects were excluded because of ECG abnormalities and another four subjects failed to attend for interview because they were away from Southampton at the time. Men with previously diagnosed diverticular disease were also excluded ( 0 patients, one control subject).

All subjects were investigated for the presence of diverticular disease by taking plain radiographs of the abdomen 48 hours after oral barium sulphate (Micropaque, Nicholas Laboratories, Slough), as described by Manousos et al. (1967). The presence of colonic diverticulae was assessed by an experienced 
radiologist (P.G.), viewing all the films in random order in a single session and without knowledge of the clinical status of the subjects.

To assess the transit time, the subjects took $350 \mathrm{mg}$ carmine dye by mouth at breakfast time at least two weeks after the barium examination, and reported to us the time interval which elapsed before dye was first seen in the stool. After an overight fast, plasma glucose (by an automated glucose oxidase reaction), plasma cholesterol (by an automated LeibermannBurchard Reaction), and triglyceride (by nonane extraction, saponification, and non-enzymatic estimation of glycerol) (Postle and Goodland, 1978) were measured.

Four patients, but none of the controls, took laxatives or bran regularly. Fourteen of the patients with ischaemic heart disease were on drugs likely to disturb metabolism or bowel motility, including diuretics (nine), beta-blocking agents (nine), and clofibrate (three).

It was expected that there would be discrepancies in the social status of our ischaemic heart disease patients and the controls, because of the largely skilled technical and professional work force of the Ordnance Survey. It was appreciated that it would be necessary to exclude patients for whom there were no appropriate control subjects. Each patient was therefore matched with the control subject of the same social class nearest in age.

Statistical analysis was by McNemar's Chisquared test, for qualitative observations (Pike and Morrow, 1970) and by Student's paired $t$ test for quantitative variables.

\section{Results}

As we had expected, the social class distribution of the control subjects was biased with an absence of control subjects of social classes 4 and 5 . We therefore excluded the 12 ischaemic heart disease patients in social classes 4 and 5 and 12 control subjects of comparable age. The mean age of the remaining 28 patients was 53 years, range 36 to 65 years. Sixteen of the patients were 51 to 60 years and five were 61 to 65 years. All control subjects were within two years of the age of their matched patient. The observations made on these 28 pairs are shown in the Table.

The prevalence of diverticular disease was greater in the ischaemic heart disease patients (16 of 28 cases, $57 \%$ ) than in their matched controls (seven of $28,25 \%, \mathrm{P}<0.05)$. Of the 12 ischaemic heart disease patients in social classes 4 and 5 (mean age 55 years), three (mean age 59 years) had diverticular disease. The ischaemic heart disease patients were more obese and had higher fasting plasma glucose concentra-
Table Characteristics and prevalence of diverticular disease of colon in 28 male subjects aged $36-65$ years with ischaemic heart disease, and 28 male control subjects matched for age and social class $($ mean $\pm S D)$

\begin{tabular}{|c|c|c|c|}
\hline & $\begin{array}{l}\text { Patients with } \\
\text { IHD }\end{array}$ & $\begin{array}{l}\text { Healthy control } \\
\text { subjects }\end{array}$ & Sign \\
\hline $\begin{array}{l}\text { No. } \\
\text { Prevalence of DD } \\
\text { Mean age (yr) } \\
\text { Weight as \% ideal body } \\
\text { weight* } \\
\text { Smokers } \\
\text { Ex-smokers } \\
\text { Fasting plasma: } \\
\quad \text { Glucose } \\
\text { (mean) mmol/1 } \\
\text { Cholesterol } \\
\text { (mean) mmol/1 } \\
\text { Triglyceride } \\
\text { (mean) mmol/1 } \\
\text { Intestinal transit-time } \\
\text { (mean) h } \\
\text { Blood pressure }\end{array}$ & $\begin{array}{c}5.3 \pm 1.1 \\
6.2 \pm 0.8 \\
1.65 \pm 0.73 \\
46 \pm 41 \\
\frac{136 \pm 29}{85} \pm 13\end{array}$ & $\begin{array}{c}4.5 \pm 0.4 \\
5.9 \pm 0.9 \\
1.3 \pm 0.54 \\
37 \pm 25 \\
\frac{145}{90} \pm 13\end{array}$ & $\begin{array}{l}\mathrm{P}<0.05 \\
\mathrm{NS} \\
\mathrm{P}<0.05 \\
\mathrm{NS}\end{array}$ \\
\hline
\end{tabular}

*Ideal body weight based upon the data of Metropolitan Life Insurance Co. (1959).

NS: not significant.

tions; plasma lipids were not significantly different. Mean intestinal transit time and blood pressure were also not significantly different between the two groups.

Six of the 28 patients, of whom five had diverticular disease, were non-smokers and another two had stopped smoking several years before. The seven patients who smoked until their myocardial infarction but not subsequently were regarded as smokers. There was no significant difference in the number of smokers in the two groups, but only one nonsmoker in the control group had diverticular disease.

When comparisons of fasting plasma glucose, cholesterol, triglyceride, transit time, and blood pressure in subjects with and without diverticular disease were made, no significant differences were found, irrespective of their clinical status (data not shown).

\section{Discussion}

We have shown that patients with ischaemic heart disease are significantly more likely to have diverticular disease than controls matched for age and social class. To our knowledge, this is the first objective study to assess this possible association. Trowell and associates (1974) suggested that a deficiency of dietary fibre might be a common aetiological factor to account for the similar geographical distribution of ischaemic heart disease and diverticular disease and their apparently increasing frequency in western 
communities. In a recently reported survey of the dietary habits of British men between 1956 and 1966, those found to have a high intake of dietary fibre from cereal were noted to have developed less clinical coronary heart disease by the end of 1976 (Morris et al., 1977). Furthermore, in a necropsy study of diverticular disease, Hughes (1969) noted an increased frequency of the disorder in subjects with subjectively more severe atheroma of the aorta, although he interpreted this finding with caution.

Our study was confined to male subjects under 66 years, as the increasingly high incidence of both diverticular disease and ischaemic heart disease in the elderly might mask any association between the two conditions.

Because of this association, one might expect subjects with diverticular disease to have raised cholesterol concentration, but this was not evident in our study. However, reports of the effects of dietary fibre on serum cholesterol have varied (Lancet, 1977), while the role of hypercholesterolaemia in the aetiology of ischaemic heart disease is also still controversial.

The relationship that we have demonstrated between asymptomatic diverticular disease and overt ischaemic heart disease does not necessarily incriminate lack of dietary fibre as a common aetiological factor. Ischaemic heart disease probably has a multifactorial basis (Dolder and Oliver, 1975) and the same is possibly true of diverticular disease. The association between the two may result from other metabolic effects of dietary fibre. Trowell (1972) has also pointed out that pulmonary embolism is less common in the developing countries, but we have not assessed the possibility that fibre deficiency may alter blood coagulability,
Professor K. G. M. M. Alberti and Dr D. Barker gave helpful advice.

\section{References}

Brodribb, A. J. M. (1977). Treatment of symptomatic diverticular disease with a high-fibre diet. Lancet, 1, 664666.

Dolder, M. A., and Oliver, M. F. (1975). Myocardial infarction in young men. Study of risk factors in nine countries. British Heart Journal, 37, 493-503.

Findlay, J. M., Smith, A. N., Mitchell, W. D., Anderson, A. J. B., and Eastwood, M. A. (1974). Effects of unprocessed bran on colon function in normal subjects and in diverticular disease. Lancet, 1, 146-149.

Hughes, L. E. (1969). Postmortem survey of diverticular disease of the colon. 1. Diverticulosis and diverticulitis. Gut, 10, 336-344.

Jenkins, D. J. A., Leeds, A. R., Gassull, M. A.. Cochet, B., and Alberti, K. G. M. M. (1977). Decrease in postprandial insulin and glucose concentrations by guar and pectin. Annals of Internal Medicine, 86, 20-23.

Lancet (1977). Dietary fibre (Editorial). Lancet, 2, 337-338.

Manousos, O. N., Truelove, S. C., and Lumsden, K. (1967). Transit times of food in patients with diverticulosis or irritable colon syndrome and normal subjects. British Medical Journal, 3, 760-762.

Metropolitan Life Insurance Co. (1959). Quoted in Documenta Geigy Scientific Tables (1962), 6th edn. Edited by K. Diem. Geigy: Manchester.

Morris, J. N., Marr, J. W., and Clayton, D. G. (1977). Diet and heart: a postscript. British Medical Journal, 2, 1307-1314.

Pike, M. C., and Morrow, R. H. (1970). Statistical analysis of patient-control studies in epidemiology. British Journal of Preventive and Social Medicine, 24, 42-44.

Postle, A. D., and Goodland, F. C. (1978). Comparison of three automated methods of serum triglyceride analysis. Annals of Clinical Biochemistry, 15, 18-24.

Trowell, H. (1972). Ischaemic heart disease and dietary fibre. American Journal of Clinical Nutrition, 25, 926-932.

Trowell, H., Painter, N., and Burkitt, D. (1974). Aspects of the epidemiology of diverticular disease and ischemic heart disease. American Journal of Digestive Diseases, 19 , 864-873. 